\title{
Perceived Sexual Harassment at Work: Meta-Analysis and Structural Model of Antecedents and Consequences
}

\author{
Gabriela Topa Cantisano ${ }^{1}$, J. F. Morales Domínguez ${ }^{1}$, and Marco Depolo² \\ ${ }^{1}$ Universidad Nacional de Educación a Distancia, Spain \\ ${ }^{2}$ Università degli Studi di Bologna, Italy
}

\begin{abstract}
Although sexual harassment has been extensively studied, empirical research has not led to firm conclusions about its antecedents and consequences, both at the personal and organizational level. An extensive literature search yielded 42 empirical studies with 60 samples. The matrix correlation obtained through meta-analytic techniques was used to test a structural equation model. Results supported the hypotheses regarding organizational environmental factors as main predictors of harassment.

Keywords: sexual harassment, meta-analysis, structural equation modeling
\end{abstract}

\begin{abstract}
Pese a que el acoso sexual ha sido extensamente estudiado, la investigación empírica no ha llegado a conclusiones firmes relativas a sus antecedentes y consecuencias personales y organizacionales. Una extensa búsqueda de la literatura arroja 42 estudios empíricos con 60 muestras que son sometidos a técnicas meta-analíticas. La matriz de correlaciones obtenida por técnicas meta-analíticas ha sido usada para probar un modelo de ecuaciones estructurales. Los resultados apoyan las hipótesis que indican que los factores del ambiente organizacional son los predictores principales del acoso.

Palabras clave: acoso sexual, meta-análisis, modelos de ecuaciones estructurales
\end{abstract}

Correspondence concerning this article should be addressed to Gabriela Topa Cantisano, Dpto. Psicología Social y de las Organizaciones, UNED, C/ Juan del Rosal, 10, 28040 Madrid (Spain). Phone: +34 91398 8911. E-mail: gtopa@psi.uned.es

Translation: Virginia Navascués Howard 
For the last twenty years, empirical research has accumulated evidence of the negative effects of sexual harassment $(\mathrm{SH})$ for workers, both in North America and in the European Union (Bjorkqvist, Osterman, \& HjeltBack, 1994; Fitzgerald, Drasgow, \& Magley, 1999; Gunnarsdottir, Raafnsdottir, Helgadottir, \& Tomasson, 2003). This phenomenon severely threatens equal opportunity and, in particular, the advancement of the female career. Moreover, it has been classified as a very severe fault (RD Legislative 5/2000 of August 4, Section 1, Art. 8), despite which SH still affects $14.5 \%$ of the workers and $18.3 \%$ of the women according to the latest study carried out in Spain.

Although there is some debate about the definition of $\mathrm{SH}$, most researchers agree that it is a psychological experience of undesired, offensive, and threatening sexual behavior, which takes place at the work setting (Fitzgerald, Drasgow, et al., 1999; Gruber \& Bjorn, 1982). Judicially, it is defined as a form of sexual discrimination that includes two behaviors: quid pro quo and a hostile environment. The first implies threats or bribery of sexual content used to make work-related decisions. The second includes dirty jokes, comments, and touching the other person, which interferes with work or produces an intimidating, hostile, or offensive environment. This concept may be excessively constrained, because many sexually harassing behaviors that are not felonious are nevertheless stressing and harmful for the victims and their organizations (Cortina \& Wasti, 2005). Despite the profusion of empirical studies, discordant results have been detected, in particular when comparing studies with samples from different occupational sectors, evaluations of the perception of harassment measured with different instruments, and, especially, in studies in which samples from different continents participate. Up to the present, various quantitative reviews of this issue have been performed (Ilies, Hauserman, Schowochau \& Stibal, 2003; Lapierre, Spector, \& Leck, 2005; Rotundo, Ngu, \& Sackett, 2001) but all of them have adopted a partial focus point or have only concentrated on one aspect of the problem, failing to base an global explanatory model on the antecedents and consequences of SH at work.

The oldest review (Rotundo et al., 2001) only examines whether or not there are significant differences among the perceivers of SH behaviors depending on their gender, but it does not consider other kinds of possible moderators nor does it examine the variables that can be considered antecedents or consequences in the organizational context. The work of Ilies and colleagues (2003) looks at the issue from the perspective of the incidence rates of $\mathrm{SH}$, detecting three main moderators-asking people whether they have experienced $\mathrm{SH}$, the use of probabilistic sampling techniques, and power distances in the organizations - that could account for the great differences among the incidence rates of $\mathrm{SH}$ referred to in the primary studies. Lastly, the work of Lapierre et al. (2005) studies the influence that SH behaviors at work can have on workers' global job satisfaction, using a procedure that compares the cases of harassment with sexual content with those that lack this connotation, but without examining other kinds of antecedents and consequences.

In short, the preceding meta-analytic studies indicate the appropriateness of conducting quantitative reviews of the empirical studies, but they have not yet presented solid support for a global model of the antecedents and consequences of SH. The purpose of this study is to make up for this deficiency by combining the meta-analytic procedures with structural equation models, according to the univariate methodology recommended by various authors (Viswesvaran \& Ones, 1995).

The preceding qualitative reviews have identified various explanations of the antecedents and consequences of SH. The sociocultural model proposes as causes the power and status differences between the sexes, which are socially legitimized, and it underscores the origin of $\mathrm{SH}$ in the patriarchal society (Gruber \& Bjorn, 1982; Rospenda, 2002). Gender is established as the first predictor of $\mathrm{SH}$ risk, and age and civil status are indicated among the individual correlates. Other models are based on the vulnerability of the victims because of their sociocultural characteristics (Bergman \& Drasgow, 2003) or their personality traits. As with mobbing, models are beginning to emerge that focus on the processes of social interaction in work organizations, which can act as predictors (Fitzgerald, Drasgow et al., 1999). In these models, the key elements are the victim's processes of appraisal of the threatening nature of the situation and her resources to cope with it. For these studies, organizational characteristics-tolerance or proportion of women-are effective predictors of SH. Organizational tolerance is the degree to which an organization is perceived as being sensitive to SH. Job-gender context is defined in two ways: as the proportion of women and the degree to which a profession is stereotypically feminine. These organizational characteristics interact with personal aspects such as previous abuse or the victim's beliefs, to influence the results. Regarding the effects, almost all authors (Glomb, Richman, Hulin, \& Drasgow, 1997; Harned, Ormerod, Palmieri, Collinswoth, \& Reed, 2002; Ragins, \& Scandura, 1995) coincide in proposing a pattern of negative relations with desirable consequences, such as psychological wellbeing, job satisfaction, and organizational commitment, and at the same time, a positive influence on undesirable consequences, such as stress, job withdrawal intention, and health complaints. A small number of studies (Jensen, \& Gutek, 1982) explore people's strategies to deal with SH.

Despite the fact that the empirical studies achieve consistent results, considerable discrepancies are observed. For example, some studies (Cortina, Fitzgerald, \& Drasgow, 2002) refer to correlations of .13 between organizational tolerance and $\mathrm{SH}$, and others of .49. Among 
the consequences, satisfaction with the supervisor only has a correlation of -.07 in a study (Wasti, Bergman, Glomb, \& Drasgow, 2000) carried out in Turkey, whereas other studies (Munson, Hulin, \& Drasgow, 2000) refer to values of about -.40. Although three meta-analyses (Ilies et al., 2003; Lapierre et al., 2005; Rotundo et al., 2001) of SH have been carried out, none of them developed an integrative model of its antecedents and consequences. In view of these disparities, it could be concluded that this research area could benefit from the application of metaanalytic procedures. Specifically, the current review proposes: (a) to effect a quantitative synthesis of the results of the preceding empirical studies, overcoming the partial focus points employed in previous quantitative reviews; (b) to analyze the possible influence of a broader range of moderating variables, specifically, to compare studies with samples from North America and Europe; and (c) to test an integrative model by structural equation analysis based on a correlation matrix derived from the metaanalysis.
Based on the above-mentioned literature, in this review, the following hypotheses are formulated:

1. Significant effect sizes are expected between the antecedents and $\mathrm{SH}$ on the one hand, and between $\mathrm{SH}$ and its consequences, on the other.

2. On the basis of the importance of the psychosocial factors, we expect:

a. A higher effect size of the antecedent of social interaction, specifically, social support

b. Lower effect sizes of the organizational antecedents: tolerance and job-gender context

3. On the basis of the impact on employees' social relations, we expect:

a. Higher effect sizes of the consequences referring to Coworker satisfaction and supervisors

b. Lower effect sizes of the consequences referring to concrete work aspects, such as job satisfaction, job withdrawal, or performance.

The hypothesized model of relations of the antecedents and consequences is displayed in Figure 1.

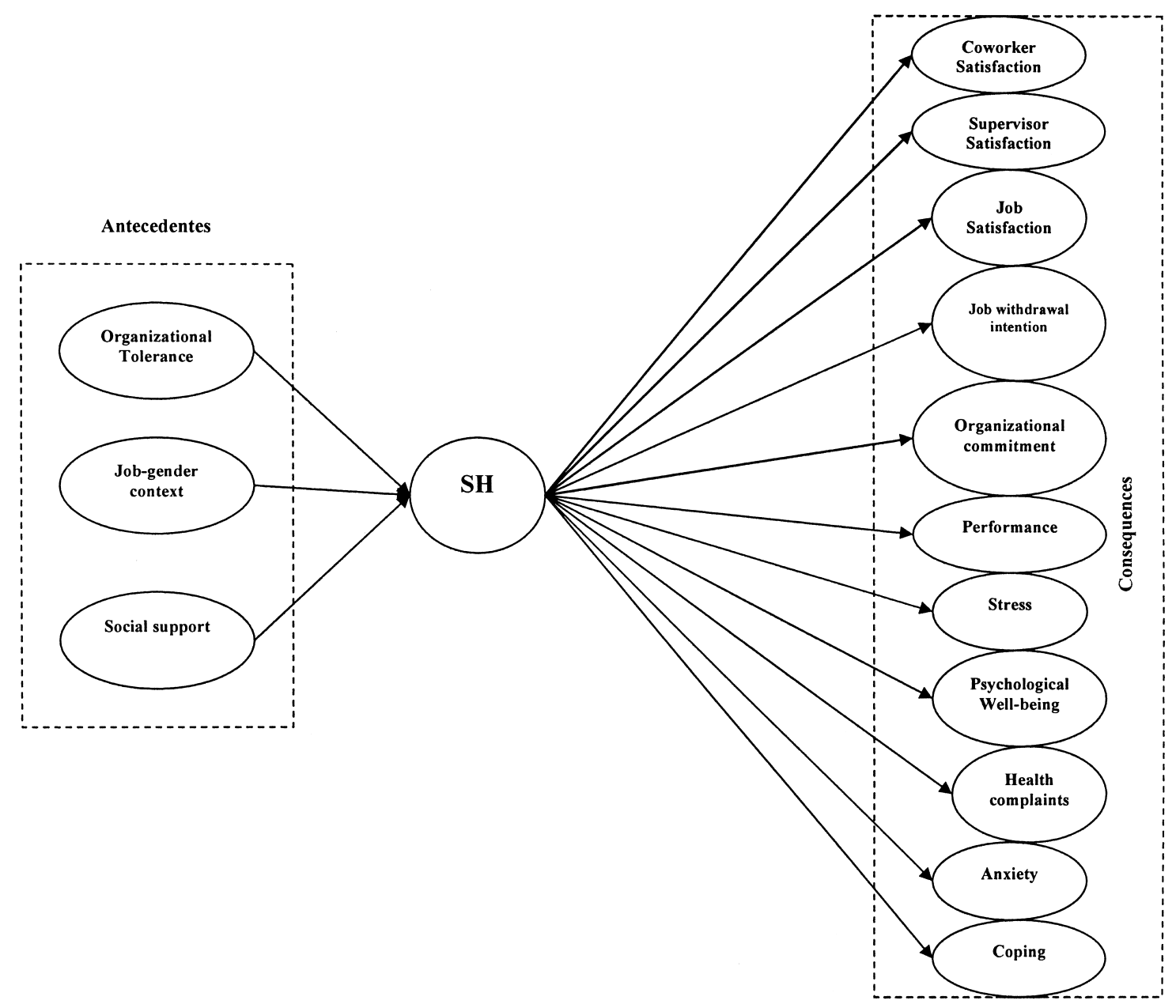

Figure 1. Theoretical model of antecedents and consequences of sexual harassment (SH). 


\section{Method}

\section{Location of the Studies}

In order to identify the relevant studies, we carried out an extensive search in computerized databases (PsycInfo, PsycArticles, ERIC, Academic Search Premier, Business Search Premier, and Econlit), using sexual harassment, sexual assault and aggression as keywords, in an attempt to identify studies published up to 2005 in English, French, Italian, or Spanish. We also performed manual searches in scientific journals (Violence and Victims, Aggressive Behavior, Aggression, Violence against Women, Psychology Women Quarterly). The reference sections of the aforementioned meta-analyses were used to recover studies, and we also tried to locate unpublished works by contacting with researcher networks, however, without success. The studies had to fulfill two conditions to be included: (a) they must provide a measure of the relation between $\mathrm{SH}$ and one or more antecedents or consequences, (b) they must refer to $\mathrm{SH}$ at work. Studies on bullying, experiments of situation labeling, and mobbing were generally excluded. The initial review provided 149 studies, of which 42 published empirical works were retained, with 60 independent samples and 106,948 participants. The chief reason for discarding studies was the absence of $r$ or of other statistics to calculate it. The total number of empirical studies included in the review was published between 1982 and 2005 and all of them were written in English.

\section{Coding}

Three groups of categorical and continuous moderating variables were coded: (a) methodological variables of the study: the instrument used to assess SH (either the Sexual Experiences Questionnaire, SEQ, Fitzgerald, Magley, Drasgow, \& Waldo, 1999, or another one); (b) methodological variables of the sample: gender (percentage of women), mean age of sample of victims, occupational sector (military, educational, health, others), mean permanence (in years) in the organization; and (c) contextual variables: source of the study (North America, European Union, other). The process was carried out by two independent evaluators who, after being trained in the procedure, analyzed $33 \%$ of the studies and reached an adequate level of agreement $(r=.87)$. Discrepancies were resolved by reviewing the coding manual.

\section{Data Analysis}

The effect size index was Pearson's correlation $(r)$ because most of the studies express their results in this metric. If the study did not provide $r$, it was calculated from other statistics. Fisher's $Z r$ transformation and SPSS macros (Lipsey \& Wilson, 2001) were used. To avoid threats to independence, we collected just one effect size per study, except for the cases that provided more than one independent sample. To appraise separately the mean effect size between $\mathrm{SH}$ and its antecedents or consequences in each metaanalysis, we used Cohen's (1988) criterion, according to which values of about $r=.10$ are considered of low magnitude, $r=.25$ are average, and $r=.40$ are high. Moreover, if zero was not included in the confidence interval, the null hypothesis stating that the relation between $\mathrm{SH}$ and its antecedent or consequent is equal to zero could be rejected at the level of $p=.05$. One problem in the interpretation of mate-analytic results is the potential bias of the mean effect size due to sampling error or to systematic omission of studies that are hard to locate. According to Orwin (1983), the "tolerance index of null results" should be calculated and there must be more than 300 unpublished studies (and not recovered by the meta-analyst) for the results to be annulled. However, this statement should be qualified because the index by categories yields small values in some of these categories. Therefore, we can conclude that publication bias is not very likely to threaten the results severely.

\section{Meta-Analytical Structural Equation Models}

The combination of meta-analysis with structural equation models allows testing broader theoretical models based on the findings of multiple studies, and the procedure is applied to various issues (Carr, Schmidt, Ford, \& DeShon, 2003). In this study, the fit of a causal model of antecedents and consequences of SH (see Figure 1) was examined with a meta-analytical correlation matrix of pairs of variables. Some of the predictors or results included in the review were eliminated from the meta-analytical matrix because no studies were found that assessed these pairs of variables (i.e., social support-organizational tolerance). The structural equation model assumes a constant sample size for all the cells, but the meta-analytical matrix presented unequal values of $N$. Therefore, the harmonic mean $(N=254)$ of the values of $N$ is recommended, which is the procedure we followed.

The model tested presents 4 exogenous variables and 7 endogenous variables and we used the generalized least squares procedure with the AMOS 6 statistical package. The fit of the model was assessed using chi square, the associated level of probability, and indicators such as the goodness of fit index (GFI), the adjusted goodness of fit index (AGFI), and the root mean square residual (RMSR), as recommended by Byrne (2001). To compare the models, we also used indexes such as the Akaike information criterion (AIC) and the Bayesian information criterion (BIC), which penalize the less parsimonious models. We used the procedure of re-specification of the model from the critical ratios associated with the parameters and from the modification indexes that indicated that changes in the model that would improve its fit. 
Results

\section{Description of the Studies}

The total number of works included in this review provided a sample of 106,948 participants $(S D=4285.83)$, with a mean age of 36.6 years $(S D=5.4)$, and a mean permanence in the organization of 8.3 years $(S D=3)$. Most of the works were from North America (74\%), $11.7 \%$ were European, and the rest were from other countries $(1.7 \%$ from Australia, 1.7\% from China, 1.7\% from Turkey, 3.3\% from Israel, and $1.7 \%$ used combined samples). Fifty percent of the studies included workers from diverse sectors, $28.3 \%$ were military personnel, $10 \%$ were from the educational

Table 1

Mean Weighted Effect Sizes for each Meta-Analysis

\begin{tabular}{|c|c|c|c|c|c|c|c|c|}
\hline \multirow[b]{2}{*}{ Variables } & \multirow[b]{2}{*}{$k$} & \multirow[b]{2}{*}{ Total $N$} & \multirow[b]{2}{*}{ Weighted $r$} & \multirow[b]{2}{*}{$S D r$} & \multicolumn{2}{|c|}{ C.I. $95 \%$} & \multirow[b]{2}{*}{$Q(d f)$} & \multirow{2}{*}{$\begin{array}{l}\text { Tolerance index } \\
\text { of null results }\end{array}$} \\
\hline & & & & & $\mathrm{Ll}$ & $\mathrm{Lu}$ & & \\
\hline \multicolumn{9}{|l|}{ Antecedents } \\
\hline Organizational tolerance & 15 & 44,998 & .19 & .005 & .18 & .20 & $265.90(14)^{* * *}$ & 9 \\
\hline Job-gender context & 16 & 70,492 & -.18 & .004 & -.18 & -.17 & $563.71(15)^{* * *}$ & 21 \\
\hline Social support & 7 & 10,726 & -.27 & .009 & -.29 & -.25 & $49.66(6)^{* * *}$ & 11 \\
\hline \multicolumn{9}{|l|}{ Consequences } \\
\hline Supervisor satisfaction & 27 & 87,139 & -.25 & .003 & -.25 & -.24 & $349.54(26)^{* * *}$ & 40 \\
\hline Coworker satisfaction & 26 & 85,621 & -.26 & .003 & -.26 & -.25 & $123.98(25) * * *$ & 39 \\
\hline Job satisfaction & 41 & 100,878 & -.21 & .003 & -.21 & -.20 & $525.81(40)^{* * *}$ & 58 \\
\hline Organizational commitment & 20 & 92,041 & -.20 & .003 & -.21 & -.20 & $315.97(19)^{* * *}$ & 28 \\
\hline Job withdrawal intention & 21 & 17,392 & .13 & .008 & .12 & .15 & $78.61(20)^{* * *}$ & 16 \\
\hline Coping strategies & 4 & 2,099 & .39 & .02 & .34 & .43 & $15.81(3)^{* *}$ & 9 \\
\hline Psychological well-being & 24 & 86,340 & -.26 & .003 & -.27 & -.25 & $326.69(23) * * *$ & 36 \\
\hline Health complaints & 25 & 84,772 & .24 & .003 & .23 & .25 & $490.85(24)^{* * *}$ & 13 \\
\hline Stress & 24 & 9,592 & .14 & .012 & .12 & .16 & $47.93(23)^{* *}$ & 17 \\
\hline Performance & 9 & 57,280 & -.23 & .004 & -.23 & -.21 & $191.35(8)^{* * *}$ & 13 \\
\hline Anxiety & 3 & 844 & .19 & .03 & .12 & .26 & $7.99(2)^{* *}$ & 2 \\
\hline
\end{tabular}

Note. $k=$ number of correlations. $\mathrm{Ll}=$ lower limit; $\mathrm{Lu}=$ upper limit.

$* p<.05 . * * p<.01 . * * * p<.001$.

Table 2

Weighted Analysis of Variance of Antecedents and Consequences as a Function of the Measuring Instrument

\begin{tabular}{|c|c|c|c|}
\hline \multirow[b]{2}{*}{ Variables } & \multirow[b]{2}{*}{$Q b(d f) / Q w(d f)$} & \multicolumn{2}{|c|}{ Effect Size $(S D)$} \\
\hline & & SEQ & Other Instruments \\
\hline \multicolumn{4}{|l|}{ Antecedents } \\
\hline Organizational tolerance & $1.66(1) / 264.25(13)^{* * *}$ & $.19(.005)$ & $.22(.02)$ \\
\hline Job-gender context & $1.25(1) / 562.46(14) * * *$ & $-.18(.004)$ & $-.15(.03)$ \\
\hline Social support & $29.47(1)^{* * *} / 20.18(5)^{*}$ & $-.29(.01)$ & $-.17(.02)$ \\
\hline \multicolumn{4}{|l|}{ Consequences } \\
\hline Supervisor satisfaction & $3.41(1)++/ 346.13(25)^{* * *}$ & $-.25(.003)$ & $-.22(.02)$ \\
\hline Coworker satisfaction & $25.33(1)^{* * *} / 98.65(24)^{* * *}$ & $-.27(.003)$ & $-.11(.03)$ \\
\hline Job satisfaction & $30.28(1) * * * / 495.53(39) * * *$ & $-.22(.003)$ & $-.15(.01)$ \\
\hline Organizational commitment & $9.49(1)^{* *} / 306.48(18)^{* * *}$ & $-.21(.003)$ & $-.13(.03)$ \\
\hline Job withdrawal intention & $.12(1) / 78.49(19)^{* * *}$ & $.14(.008)$ & $.15(.03)$ \\
\hline Coping strategies & $15.69(1)^{* * *} / .11(2)$ & $.24(.04)$ & $.44(03)$ \\
\hline Psychological well-being & $5.66(1) * / 321.04(22)^{* * *}$ & $-.27(.003)$ & $-.21(.02)$ \\
\hline Health complaints & $.11(1) / 490.75(23) * * *$ & $.24(.003)$ & $.25(.02)$ \\
\hline Stress & $.16(1) / 47.77(22)^{* *}$ & $.14(.01)$ & $.13(.02)$ \\
\hline Performance & $8.05(1)^{*} / 183.30(7)^{* * *}$ & $-.23(.004)$ & $-.06(.06)$ \\
\hline
\end{tabular}

++ tendency value. $* p<.05 . * * p<.01 . * * * p<.001$. 
area, and 5\% from the health area. Forty-five percent of the works employed the SEQ (Fitzgerald, Magley, et al., 1999) and the rest used other instruments.

Mean effect sizes are displayed in Table 1. Mean values were obtained in almost all cases and the results show sufficient variability, as the value of $Q$ was always statistically significant. Therefore, we used weighted analysis of variance (fixed effects model) and weighted multiple regression analysis with a fixed effects model to verify the existence of moderating variables.
The models based on the type of instrument employed (see Table 2) account for the total variability in the coping strategies. In contrast, they only explain part of this variability in the analysis of satisfaction with the supervisor and coworkers, social support, job satisfaction, commitment, and psychological well-being, leaving a large amount of variability unexplained. The least efficient models were those based on the participants' source (see Table 3), which only reached significant values for $Q b$ in the analyses of satisfaction with the

Table 3

Weighted Analysis of Variance of Antecedents and Consequences as a Function of the Sample Source

\begin{tabular}{|c|c|c|c|c|}
\hline \multirow[b]{2}{*}{ Variables } & \multirow[b]{2}{*}{$Q b(d f) / Q w(d f)$} & \multicolumn{3}{|c|}{ Effect Size $(S D)$} \\
\hline & & North America & Europe & Other \\
\hline \multicolumn{5}{|l|}{ Antecedents } \\
\hline Organizational tolerance & $.02(1) / 265.88(13)^{* * *}$ & $.19(.005)$ & & $.20(.05)$ \\
\hline Job-gender context & $.31(1) / 563.40(14)^{* * *}$ & $-.18(.004)$ & & $-.21(.05)$ \\
\hline Social support & $40.92(2) * * * / 8.73(4)$ & $-.30(.01)$ & $-.14(.03)$ & $-.07(.06)$ \\
\hline \multicolumn{5}{|l|}{ Consequences } \\
\hline Supervisor satisfaction & $26.90(2)^{* * *} / 322.64(24)^{* * *}$ & $-.25(.003)$ & $-.15(.02)$ & $-.07(.05)$ \\
\hline Coworker satisfaction & $.06(1) / 123.92(24)^{* * *}$ & $-.26(.003)$ & & $-.28(.05)$ \\
\hline Job satisfaction & $25.38(2)^{* * *} / 487.13(34)^{* * *}$ & $-.22(.003)$ & $-.15(02)$ & $-.12(.03)$ \\
\hline Organizational commitment & $21.90(2)^{* * *} / 294.08(17)^{* * *}$ & $-.21(.003)$ & $-.02(.04)$ & $-.09(.11)$ \\
\hline Job withdrawal intention & $3.45(2) / 75.16(18)^{* * *}$ & $.14(.008)$ & $.17(.06)$ & $.19(.03)$ \\
\hline Psychological well-being & $9.69(2)^{* *} / 317.00(21)^{* * *}$ & $-.26(.003)$ & $-.19(.03)$ & $-.19(.05)$ \\
\hline Health complaints & $1.98(2) / 488.87(22)^{* * *}$ & $.24(.003)$ & $.18(.05)$ & $.25(.05)$ \\
\hline Stress & $3.06(2) / 44.87(21)^{* *}$ & $.15(.01)$ & $.12(.03)$ & $.10(.03)$ \\
\hline
\end{tabular}

++ tendency value. ${ }^{*} p<.05 . * * p<.01 . * * p<.001$.

Table 4

Weighted Analysis of Variance of Antecedents and Consequences as a Function of the Occupational Sector of the Sample

\begin{tabular}{|c|c|c|c|c|c|}
\hline \multirow[b]{2}{*}{ Variables } & \multirow[b]{2}{*}{$Q b(d f) / Q w(d f)$} & \multicolumn{4}{|c|}{ Effect Size $(S D)$} \\
\hline & & Military & Miscellaneous & Education & Health \\
\hline \multicolumn{6}{|l|}{ Antecedents } \\
\hline Organizational tolerance & $68.62(2)^{* *} / 197.28(12)^{* *}$ & $.18(.005)$ & $.30(.02)$ & $.35(.04)$ & \\
\hline Job-gender context & $4.76(2) / 558.95(13)^{* *}$ & $-.18(.004)$ & $-.17(.02)$ & $-.03(.07)$ & \\
\hline Social support & $31.60(2) * * / 12.15(2)+$ & $-.29(.01)$ & $-.33(.03)$ & & $-.14(.03)$ \\
\hline \multicolumn{6}{|l|}{ Consequences } \\
\hline Supervisor satisfaction & $26.73(3) * * / 322.80(23)^{* *}$ & $-.25(.004)$ & $-.22(.01)$ & $-.33(.03)$ & $-.15(.03)$ \\
\hline Coworker satisfaction & $5.82(2)+/ 118.16(23) * *$ & $-.26(.003)$ & $-.23(.01)$ & $-.30(.03)$ & \\
\hline Job satisfaction & $77.58(3)^{* *} / 448.55(37)^{* *}$ & $-.22(.003)$ & $-.14(.01)$ & $-.22(.07)$ & $-.11(.03)$ \\
\hline Organizational commitment & $30.95(2)^{* *} / 285.03(17)^{* *}$ & $-.21(.003)$ & $-.13(.02)$ & & $.00(.06)$ \\
\hline Job withdrawal intention & $18.61(3)^{* *} / 59.99(17)^{* *}$ & $.11(.01)$ & $.16(.01)$ & $.23(.03)$ & $.17(.06)$ \\
\hline Psychological well-being & $60.64(3) * * / 266.05(20) * *$ & $-27(.003)$ & $-.16(.02)$ & $-.23(.04)$ & $-.19(.03)$ \\
\hline Health complaints & $47.13(2)^{* *} / 443.17(20)^{* *}$ & $.24(.004)$ & $.14(.02)$ & $.24(.07)$ & \\
\hline Stress & $5.33(2)++$ / $42.61(21)^{*}$ & $.10(.04)$ & $.14(.01)$ & $.23(.04)$ & \\
\hline Performance & $8.05(1)+/ 183.29(7)^{* *}$ & $-.23(.004)$ & & & $-.06(.06)$ \\
\hline
\end{tabular}

++ tendency value. ${ }^{*} p<.05 . * * p<.01 . * * * p<.001$. 
Table 5

Weighted Multiple Regression of Antecedents and Consequences of Sexual Harassment as a Function of Mean Permanence in the Organization, Mean Age of the Sample of Victims, and the Proportion of Women in the Sample

\begin{tabular}{lrrr}
\hline Variable & \multicolumn{1}{c}{$Q_{\mathrm{R}}(d f)$} & $Q_{\mathrm{E}}(d f)$ & \\
\hline Antecedents & & $R^{2}$ \\
Organizational tolerance & $19.64(3)^{* *}$ & $129.47(3)^{* * *}$ & .13 \\
Job-gender context & $85.92(3)^{* * *}$ & $464.08(6)^{* * *}$ & .16 \\
Social support a & $28.2(2)^{* * *}$ & $21.45(4)^{* * *}$ & .57 \\
Consequences & & $292.93(11)^{* * *}$ & .08 \\
Supervisor satisfaction & $26.08(3)^{* * *}$ & $73.09(10)^{* * *}$ & .23 \\
Coworker satisfaction & $21.49(3)^{* * *}$ & $278.65(20)^{* * *}$ & .13 \\
Job satisfaction & $40.66(3)^{* * *}$ & $261.95(9)^{* * *}$ & .07 \\
Organizational commitment & $20.13(3)^{* * *}$ & $59.54(12)^{* * *}$ & .05 \\
Job withdrawal intention a & $3.65(2)$ & $206.99(11)^{* * *}$ & .25 \\
Psychological well-being & $69.1(3)^{* * *}$ & $371.61(13)^{* * *}$ & .13 \\
Health complaints & $55.03(3)^{* * *}$ & $33.02(17)^{*}$ & .22 \\
Stress a & $9.08(2)^{* *}$ & $29.47(5)^{* * *}$ & .85 \\
Performance & $161.87(3)^{* * *}$ &
\end{tabular}

a. Only the mean age of the sample and the percentage of women in the sample were used in this model.

$* p<.05$. ** $p<.01 . * * * p<.001$.

Table 6

Standardized Regression Weights of the Continuous Variables in the Weighted Multiple Regression

\begin{tabular}{|c|c|c|c|}
\hline \multirow[b]{2}{*}{ Variables } & \multicolumn{3}{|c|}{ Continuous moderating variables } \\
\hline & $\begin{array}{c}\text { Mean age of sample } \\
\text { of victims }\end{array}$ & $\begin{array}{l}\text { Mean permanence in the } \\
\text { organization (years) }\end{array}$ & $\begin{array}{l}\text { Percentage of women } \\
\text { in the sample }\end{array}$ \\
\hline \multicolumn{4}{|l|}{ Antecedents } \\
\hline Organizational tolerance & .55 & -.22 & .18 \\
\hline Job-gender context & .17 & -.06 & -.37 \\
\hline Social support & .77 & & .05 \\
\hline \multicolumn{4}{|l|}{ Consequences } \\
\hline Supervisor satisfaction & .32 & .07 & .01 \\
\hline Coworker satisfaction & -.37 & .66 & .13 \\
\hline Job satisfaction & .38 & .20 & -.02 \\
\hline Organizational commitment & .24 & .09 & .06 \\
\hline Job withdrawal intention & .14 & & -.20 \\
\hline Psychological well-being & .67 & .46 & -.08 \\
\hline Health complaints & -.13 & -.16 & .25 \\
\hline Stress & -.47 & & .05 \\
\hline Performance & .23 & -.96 & .05 \\
\hline
\end{tabular}

supervisor, social support, job satisfaction, commitment, and psychological well-being. As can be observed in Table 4, the categorical models that use the occupational sector of the sample are the most efficient to account for the variability of the studies, with the exception of meta-analysis on job-gender context and SH. In all cases, however, the value of $Q w$ was still significant, which indicates that there is still some percentage of unexplained variance.
As shown in Tables 5 and 6, the weighted multiple regression analysis accounted for part of the variability of the results, except in the case of job withdrawal intention, for which the values of $Q_{R}$ were nonsignificant. The data show that permanence in the organization and age had higher standardized regression weights, whereas the weights of the proportion of women in the sample were nonsignificant.

Structural equation models test all the relations among antecedents and consequences at the same time, and allow 


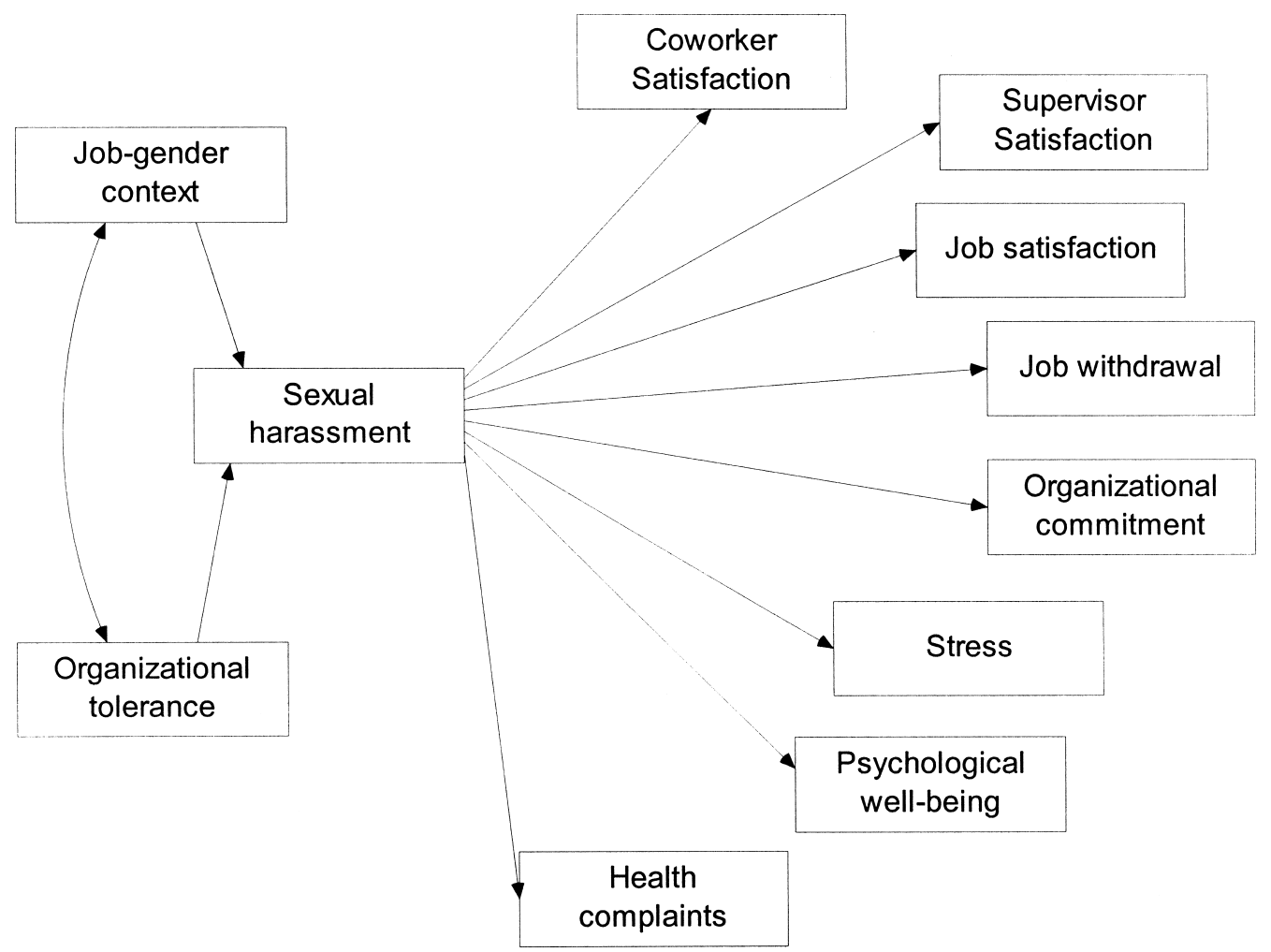

Figure 2. Initial structural equation model.

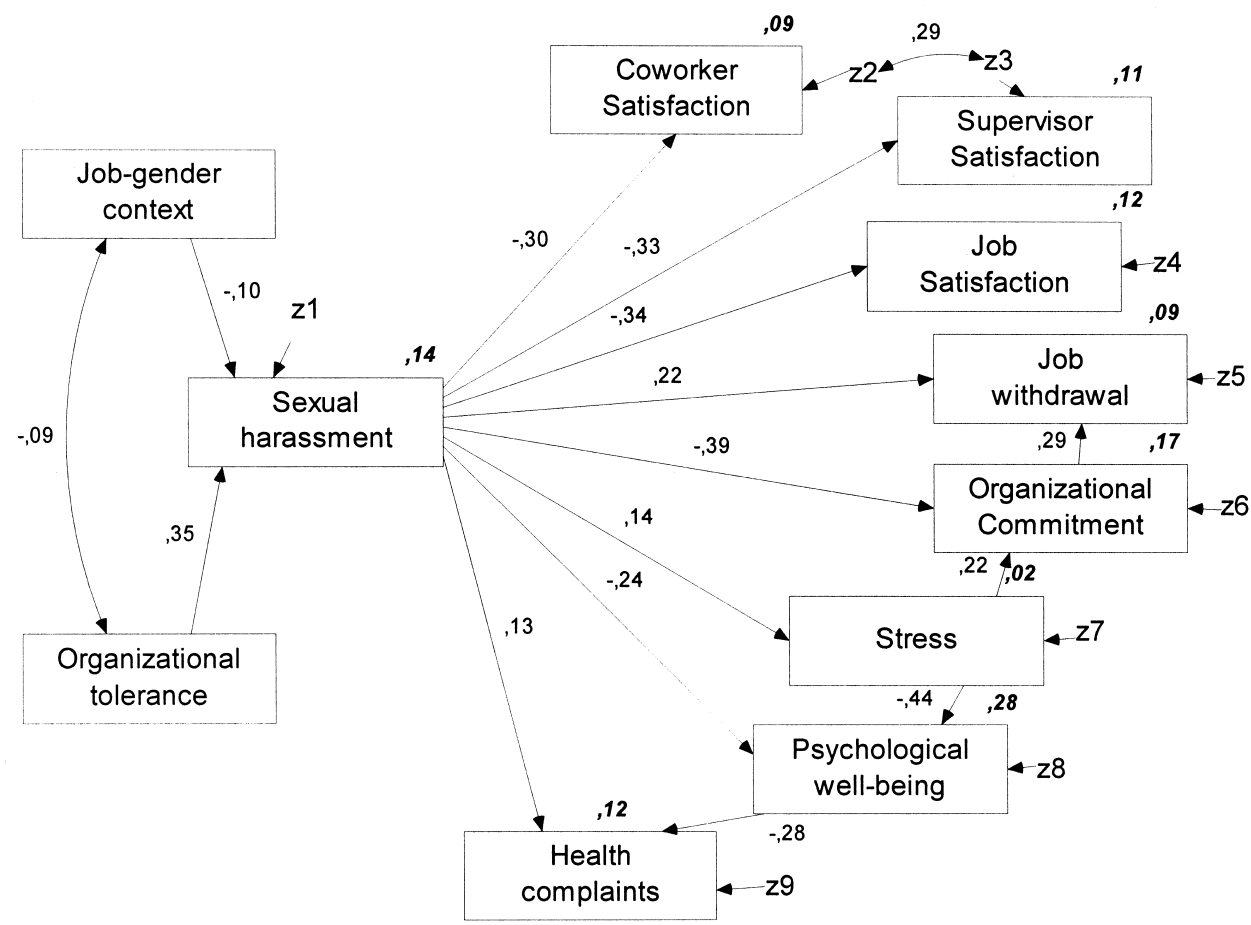

Figure 3. Standardized estimations for the final model.

Italic and boldface numbers represent the percentage of variance accounted for, the numbers without italics over the straight arrows represent the standardized regression weights, and the values over the curved arrows represent the covariance between the variables. Z1Z9 represent the standard error of regression weights. 
estimation of the indirect effects of some variables on the others. For this purpose, we started with the initial model represented in Figure 2. The chi square value was significant, $\chi^{2}(44, N=254)=188.71, p=.000$, and the indicators of global fit were improvable $(\mathrm{GFI}=.86, \mathrm{AGFI}=.79, \mathrm{AIC}=$ $232.71, \mathrm{BIC}=310.53)$ although the RMSR value $(.001)$ was adequate. A re-specified model, in which the covariances between the nonsignificant predictors were eliminated, was tested, and direct relations among some consequences of $\mathrm{SH}$ were added. The fit indicators improved, $\chi^{2}(39, N=$ $254)=114.70, p=.000, \mathrm{GFI}=.92, \mathrm{AGFI}=.86, \mathrm{RMSR}=$ $.001, \mathrm{AIC}=168.7, \mathrm{BIC}=264.21$, and the percentage of explained variance of the results increased. Based on these results, it can be concluded that the model presented in Figure 3 offers an acceptable estimation of the relations among the antecedents and consequences of SH.

\section{Discussion and Conclusions}

The main purpose of this work was to meta-analytically review the studies on $\mathrm{SH}$ at work and to offer explanatory models of the variability of the results. We also proposed to test a model of simultaneous relations among antecedents and consequences based on the findings of the metaanalytical review.

Most of the hypotheses formulated have found support in the data, although this confirmation is not at all conclusive. Although, as proposed by the hypotheses, close relations were found between the personal and organizational antecedents and consequences of $\mathrm{SH}$, it should be taken into account that some meta-analyses are based on a reduced number of studies, such as the case of social support, performance, and, especially, coping strategies and anxiety.

As predicted, among the organizational antecedents, the highest effect size corresponds to a variable of social interaction processes-social support. This evidence would favor the models that point to social interactions between superiors and subordinates or among coworkers as key variables in the explanation of the phenomenon (Luthar \& Pastille, 2000), in contrast to other theoretical frameworks that attempt to offer sociological explanations. Nevertheless, the strong relation of organizational characteristics and work environment with $\mathrm{SH}$ cannot be ignored, and it should be taken into account that these variables provide organizations with a more direct intervention mechanism for prevention.

With regard to the consequences, as predicted, the effects on social relations and on psychological and physical wellbeing have higher effect sizes, although this hypothesis is not confirmed either for anxiety or stress. In contrast, the consequences at the organizational level, such as job withdrawal intention or performance, have a more complex pattern than was predicted. Whereas a smaller effect size was observed for job withdrawal intention, one of the highest effect sizes was found for performance, and the effect sizes for job satisfaction and organizational commitment were moderate. These findings could indicate that the impact of $\mathrm{SH}$ on the results is not direct but mediated by other factors. Thus, employees may manifest the negative consequences of $\mathrm{SH}$ in the form of reduced performance although they may not have decided to quit their job. This perceived reduced performance might be a sign of the influence of intergroup productivity processes that are affected by the hostile atmosphere that is associated with $\mathrm{SH}$. When all the relations are analyzed conjointly in the structural model, some patterns vary, showing that higher impact of $\mathrm{SH}$ is observed on satisfaction with supervisors and coworkers-among the results on the personal level — and on job satisfaction and commitment_among the results at the organizational level.

Despite the fact that no specific hypotheses were formulated about the moderating variables, we could confirm that the effect sizes of organizational tolerance is very low for the studies in the military setting, perhaps because of the effect of the official Equal Opportunity programs that the North American Armed Forces have been implementing for some time, as this is the context where most of the military studies reviewed came from. In contrast, it is also observed that the studies that used standardized instruments such as the SEQ (Fitzgerald, Magley, et al., 1999) to assess the variables of interest found higher effect sizes. As this instrument operationalizes $\mathrm{SH}$ by means of a list of behaviors, it can be concluded that more reliable measures allow one to determine stronger relations between $\mathrm{SH}$ and its personal and organizational correlates. Lastly, when comparing the samples from North America and Europe or Asia, we observed that the effect size of satisfaction with the supervisor or of social support was very high for the former, whereas it was much lower for the latter two. This result requires more empirical research. The suggestions of an anonymous reviewer led the authors to verify that, when the $Q b$ test is significant, the correlations for studies from North America are systematically stronger than those from Europe, also with regard to job satisfaction, organizational commitment, and coping strategies. Likewise, in the analyses as a function of the occupational sector, we observed that when the $Q b$ test is significant and we had data from the educational sector, this sector presents the strongest correlations between $\mathrm{SH}$ and the antecedents or consequences, although in the case of job satisfaction and health problems, the military sector and the educational sector were equal.

Lastly, we would like to indicate for future research that this meta-analysis has detected certain limitations in the approach of empirical investigation to mobbing, at least in the last few years. This has led to a number of predictor variables of great interest from the psychosocial perspective that were not meta-analyzed in this review because there were only one or two empirical studies that included them. Such is the case of ambiguity and role conflict, work overload, task demands and its control, exchange processes with the leader, and the organizational culture. The explanatory limitation of 
the models of SH may reside in this aspect, as most of the models are mere replications of studies initiated by military psychology from the United States and they have overlooked the importance of the interaction of personal variables with other contextual characteristics to determine SH. Only a few studies have explored a broader range of results, taking into account the variables affected by SH, including family-work conflict, professional advancement opportunities, and perceived job safety. We also call attention to the fact that the models reviewed in the empirical studies also tend to concentrate either on macro-social indicators or on personal indicators, ignoring group variables such as perceived justice, identification with the work group, or with the organization, which could play mediating roles in the relation with $\mathrm{SH}$.

\section{Limitations of the Study and Suggestions for Future Research}

Some of the possible limitations of this study are the following: Firstly, the source of most of the data of the empirical studies is the victim's perception, which shows that the works have systematically ignored the consideration of other perspectives, such as the perceptions of supervisors and coworkers. Although in the case of SH, these same people are the perpetrators of the crime, an attempt to gather information from other sources, such as medical reports or consultations with juridical advisors, is recommended.

Secondly, although the narrative reviews recommend it repeatedly, there is a great lack of longitudinal studies in this field. This limits the possibility of establishing conclusive causal relations between variables, leaving open the issue of circularity of influences. In this sense, in this review, some variables have been considered consequences because the primary studies did so. Thus, satisfaction with supervisors and coworkers decreased because of $\mathrm{SH}$, but it is also plausible that, in an atmosphere of dissatisfaction with the social relations with one's coworkers and supervisors, there may be a higher tendency to perceive other peoples' actions as SH.

Despite all these limitations, the present study provides an explanatory model of the antecedents and consequences of $\mathrm{SH}$ in the general population.

\section{References}

(References marked with an asterisk indicate studies included in the meta-analysis.)

*Barak, A., Pitterman, Y., \& Yitzhaki, R. (1995). An empirical test of the role of power differential in originating sexual harassment. Basic and Applied Social Psychology, 17, 497-517.

*Barling, J., Rogers, G., \& Kelloway, E.K. (2001). Behind closed doors: In-home workers' experience of sexual harassment and workplace violence. Journal of Occupational Health Psychology, 6, 255-269.
*Bergman, B. (2003). The validation of the Women Workplace Culture Questionnaire: Gender-related stress and health for Swedish working women. Sex Roles, 49, 287-297.

*Bergman, B., \& Mallberg, L.R.-H. (2002). Women in a maledominated industry: Factor analysis of a Women Workplace Culture Questionnaire based on a grounded theory model. Sex Roles, 46, 311-322.

*Bergman, M.E., \& Drasgow, F. (2003). Race as moderator in a model of sexual harassment: An empirical test. Journal of Occupational Health Psychology, 8, 131-145.

*Björkqvist, K., Österman, K., \& Hjelt-Bäck, M. (1994). Aggression among university employees. Aggressive Behavior, 20, 173184.

*Brough, P., \& Frame, R. (2004). Predicting police job satisfaction and turnover intentions: The role of social support and police organisational variables. New Zealand Journal of Psychology, $33,8-16$.

*Bulger, C.A. (2001). Union resources and union tolerance as moderators of relationships with sexual harassment. Sex Roles, 45, 723-741.

Byrne, B. (2001). Structural equation modelling with AMOS, EQS, and LISREL: Comparative Approaches to testing for the factorial validity of a measuring instrument. International Journal of Testing, 1, 55-86.

Carr, J., Schmidt, A., Ford, K., \& DeShon, R. (2003). climate perceptions matter: A meta-analytic path analysis relating molar climate, cognitive and affective states and individual level work outcomes. Journal of Applied Psychology, 88, 605-619.

*Chan, D.K., STang, C., \& Chan, W. (1999). Sexual harassment. A preliminary analysis of its effects on Hong Kong women in the workplace and academia. Psychology of Women Quarterly, 23, 661-672.

Cohen, J. (1988). Statistical power analysis for the behavioral sciences. ( $2^{\text {nd }}$ ed.). Hillsdale, NJ: Erlbaum.

*Cortina, L.M. (2004). Hispanic perspectives on sexual harassment and social support. Personality and Social Psychology Bulletin, 30, 570-584.

*Cortina, L.M., Fitzgerald, L.F., \& Drasgow, F. (2002). Contextualizing Latina experiences of sexual harassment: Preliminary test of a structural model. Basic and Applied Social Psychology, 24, 295-311.

Cortina, L.M., \& Wasti, S.A. (2005). Profiles in coping: Responses to sexual harassment across persons, organizations and cultures. Journal of Applied Psychology, 90, 182-192.

*Dekker, I., \& Barling, J. (1998). Personal and organizational predictors of workplace sexual harassment of women by men. Journal of Occupational Health Psychology, 3, 7-18.

*Fitzgerald, L.F., Drasgow, F., Hulin, C.L., Gelfand, M., \& Magley, V.J. (1997). Antecedents and consequences of sexual harassment in organizations: A test of an integrated model. Journal of Applied Psychology, 82, 578-589.

*Fitzgerald, L.F., Drasgow, F., \& Magley, V.J. (1999). Sexual harassment in the Armed Forces: A test of an integrated model. Military Psychology, 11, 329-343.

Fitzgerald, L.F., Magley, V.J., Drasgow, F., \& Waldo, C.R. (1999). 
Measuring sexual harassment in the military: The Sexual Experiences Questionnaire (SEQ-DoD). Military Psychology, 11, 243-263.

*Gates, D., Fitzwater, E., \& Succop, P. (2003). Relationships of stressors, strain and anger to caregiver assaults. Issues in Mental Health Nursing, 24, 775-793.

*Glomb, T.M., Munson, L.J., Hulin, C.L., Berryman-Fink, C., \& Drasgow, F. (1999). Structural equation models of sexual harassment: Longitudinal explorations and cross-sectional generalizations. Journal of Applied Psychology, 84, 14-28.

*Glomb, T.M., Richman, W.L., Hulin, C.L., \& Drasgow, F. (1997). Ambient sexual harassment: An integrated model of antecedents and consequences. Organizational Behavior and Human Decision Processes., 71, 309-328.

*Goldenhar, L., Williams, L.J., \& Swanson, N.G. (2003). Modelling relationships between job stressors and injury and near-miss outcomes for construction labourers. Work \& Stress, 17, 218240.

*Gruber, J.E., \& Bjorn, L. (1982). The sexual harassment of women autoworkers. Work and Occupations, 9, 271-298.

*Gunnarsdottir, H.K., Raafnsdottir, G.L., Helgadottir, B., \& Tomasson, K. (2003). Psychosocial risk factors for musculoskeletal symptoms among women working in geriatric care. American Journal of Industrial Medicine, 44, 679-684.

*Harned, M.S., Ormerod, A.J., Palmieri, P.A., Collinswoth, L.L., \& Reed, M. (2002). Sexual assault an other types of sexual harassment by workplace personnel: A comparison of antecedents and consequences. Journal of Occupational Health Psychology, 7, 174-188.

*Hesson-McInnis, M., \& Fitzgerald, L.F. (1997). Sexual harassment: A preliminary test of an integrative model. Journal of Applied Social Psychology, 27, 877-901.

Ilies, R., Hauserman, N., Schowochau, S., \& Stibal, J. (2003). Reported incidence rates of work-related sexual harassment in the United States: Using meta-analysis to explain reported rate disparities. Personnel Psychology, 56, 607- 631.

*Ingram, K.M., Corning, A., \& Schmidt, L. (1996). The relationship of victimization experiences to psychological well-being among homeless women and low-income housed women. Journal of Counseling Psychology, 43, 218-227.

*Jensen, I., \& Gutek, B. (1982). Attributions and assignment of responsibility in sexual harassment. Journal of social Issues, 38, 121-136.

*Kissman, K. (1990). Women in blue-collar occupations. An exploration of constraints and facilitators. Journal of Sociology and Social Welfare, 139-149.

Lapierre, L., Spector, P., \& Leck, J. (2005). Sexual vs. nonsexual workplace aggression and victims' overall job satisfaction: A meta-analysis. Journal of Occupational Health Psychology, 10, 155- 169.

*Lim, S., \& Cortina, L.M. (2005). Interpersonal mistreatment in the workplace: The interface and impact of general incivility and sexual harassment. Journal of Applied Psychology, 90, 483 $-496$.
Lipsey, M., \& Wilson, D. (2001). Practical meta-analysis. Thousand Oaks, CA: Sage.

Luthar, H., \& Pastille, C. (2000). Modelling subordinate perceptions of sexual harassment: The role of superior-subordinate socialsexual interaction. Human Resource Management Review, 10, 211-244.

*Magley, V.J., Hulin, C.L., Fitzgerald, L.F., \& DeNardo, M. (1999). Outcomes of self-labeling sexual harassment. Journal of Applied Psychology, 84, 390-402.

*Morrow, P.C., McElroy, J C., \& Phillips, C. (1994). Sexual harassment behaviors and work-related perceptions and attitudes. Journal of Vocational Behavior, 45, 295-309.

*Munson, L.J., Hulin, C.L., \& Drasgow, F. (2000). Longitudinal analysis of dispositional influences and sexual harassment: Effects on job and psychological outcomes. Personnel Psychology, 53, 21-46.

*Murrell, A.J., Olson, J.E., \& Frieze, I.H. (1995). Sexual harassment and gender discrimination: A longitudinal study of women managers. Journal of Social Issues, 51, 139-149.

*Murry, W., Sivasubramaniam, N., \& Jacques, P.H. (2001). Supervisory support, social exchange relationships, and sexual harassment consequences. A test of competing models. The Leadership Quarterly, 12, 1-29.

*Newell, C., Rosenfeld, P., \& Culbertson, A.L. (1995). Sexual harassment experiences and equal opportunity perceptions of Navy women. Sex Roles, 32, 159 -168.

*O'Connell, B.J., \& Korabik, K. (2000). Sexual harassment: The relationship of personal vulnerability, work context, perpetrator status, and type of harassment to outcomes. Journal of Vocational Behavior, 56, 299-329.

Orwin, R. (1983). A fail-safe $\mathrm{N}$ for effect size in meta-analysis. Journal of Educational Statistics, 8, 157- 159.

*Parker, S.K., \& Griffin, M.A. (2002). What is so bad about a little name-calling? Negative consequences of gender harassment for over-performance demands and distress. Journal of Occupational Health Psychology, 7, 195-210.

*Piotrkowski, C.S. (1998). Gender harassment, job satisfaction and distress among employed white and minority women. Journal of Occupational Health Psychology, 3, 33-43.

*Ragins, B.R., \& Scandura, T.A. (1995). Antecedents and workrelated correlates of reported sexual harassment: An empirical investigation of competing hypotheses. Sex Roles, 32, 429 - 455.

*Rosen, L.N., \& Martin, L. (1998). Incidence and perceptions of sexual harassment among male and female U.S. Army soldiers. Military Psychology, 10, 239-257.

Rospenda, K.M. (2002). Workplace harassment, services utilization and drinking outcomes. Journal of Occupational Health Psychology, 7, 141-155.

Rotundo, M., Nguyen, D., \& Sackett, P. (2001). A meta-analytic review of gender differences in perceptions of sexual harassment. Journal of Applied Psychology, 86, 914-922.

*Scheneider, K.T., Swan, S., \& Fitzgerald, L.F. (1997). Job-related and psychological effects of sexual harassment in the workplace: Empirical evidence from two organizations. Journal of Applied Psychology, 82, 401-415. 
*Shaffer, M.A., Joplin, J.R., Bell, M.P., Lau, T., \& Oguz, C. (2000). Gender discrimination and job-related outcomes: A crosscultural comparison of working women in the United States and China. Journal of Vocational Behavior, 57, 395-427.

*Stedham, Y., \& Mitchell, M.C. (1998). Sexual harassment in casinos: Effects on employee attitudes and behaviors. Journal of Gambling Studies, 14, 381-400.

Viswesvaran, C., \& Ones, D. (1995). Theory testing: Combining psychometric meta-analysis and structural equations modelling. Personnel Psychology, 48, 865 -885.
*Wasti, S.A., Bergman, M.E., Glomb, T.M., \& Drasgow, F. (2000). Test of the cross-cultural generalizability of a model of sexual harassment. Journal of Applied Psychology, 85, 766-778.

*Williams, J.H., Fitzgerald, L.F., \& Drasgow, F. (1999). The effects of organizational practices on sexual harassment and individual outcomes in the Military. Military Psychology, 11, 303-328

Received October, 23, 2006 Revision received July, 12, 2007 Accepted September, 3, 2007 